\title{
Alfabetização e formação de professores: algumas reflexões sobre a leitura e a escrita
}

\author{
Literacy and teacher training: some reflections on \\ reading and writing
}

Helenise Sangoi Antunes*

Universidade Federal de Santa Maria

Resumo Este artigo apresenta reflexões sobre leitura e escrita, a partir do projeto de pesquisa "Laboratório de Alfabetização: repensando a formação de professores", que pretende estabelecer intercâmbio entre escolas em situação de vulnerabilidade social e a Universidade Federal de Santa Maria e contribuir para a formação dos acadêmicos dos cursos de Pedagogia e Educação Especial, assim como dos professores das escolas envolvidas. Adotando uma metodologia qualitativa, o projeto busca auxiliar no processo de alfabetização ao propor reflexão sobre a prática pedagógica vigente nas primeiras séries do ensino fundamental. Os resultados remetem à existência de práticas no ensino fundamental que ignoram, na maioria das vezes, a capacidade criadora dos alunos. Concluiu-se que este projeto potencializou as relações entre formação inicial e continuada de professores e práticas de leitura e escrita.

PALAVRAS-CHAVE: Alfabetização, Leitura e escrita, Formação de professores.

\begin{abstract}
This paper presents reflections on reading and writing, from the research project "Literacy Lab: rethinking teacher training" which aims to establish exchanges between socially vulnerable schools and the Federal University of Santa Maria (UFSM) and contribute to the training of undergraduates in Pedagogy and Special Education, as well as the teachers of the schools involved. Adopting a qualitative methodology based on studies of Bogdan and Bicklen (1994), the project seeks to support the literacy process by proposing reflection on the current pedagogical practices in the early years of elementary school. The results show the existence of practices in elementary school which mostly ignore the creative ability of the students. It was concluded that this project has enhanced the relationship between initial and continuous training of teachers and practices of reading and writing.
\end{abstract}

KEYWORDS: Literacy, Reading and writing, Teacher training. 


\section{Introduzindo a temática}

O trabalho desenvolvido a partir do projeto "Laboratório de Alfabetização: repensando a formação de professores" é coordenado pela profa. Dra. Helenise Sangoi Antunes e é vinculado ao Grupo de Estudo e Pesquisa sobre Formação Inicial, Continuada e Alfabetização (Gepfica) do Programa de PósGraduação em Educação da Universidade Federal de Santa Maria o qual pode ser acessado através do endereço da internet www.ufsm.br/gepfica. O referido grupo tem 10 (dez) anos de existência e é formado por professores do Centro de Educação, por alunos da graduação e pós-graduação e também por professores da rede de ensino do Estado do Rio Grande do Sul.

O projeto recebeu este nome por estar vinculado aos Laboratórios de Ensino do Departamento de Metodologia de Ensino (LAMEN) que são constituídos pelo Laboratório de Artes Cênicas, Artes Visuais, Ensino de Biologia, Ensino de Física, Ensino de História, Línguas e Ensino, Educação Matemática Escolar, Educação Musical, Ensino de Química e Alfabetização e Linguagem do Centro de Educação da Universidade Federal de Santa Maria. Dessa forma, enquanto o Laboratório de Alfabetização e Linguagem faz parte do Departamento de Metodologia de Ensino, com uma estrutura física permanente, criou-se, em 2002, o projeto que possui a proposta de ser um Laboratório de Alfabetização itinerante e móvel, que vai ao encontro das demandas de formação inicial e continuada de professores, bem como atende as demandas e dificuldades das crianças nos processos de construção da leitura e da escrita do Estado do Rio Grande do Sul.

O projeto "Laboratório de Alfabetização: repensando a formação de professores" e o convênio nacional entre o Gepfica da UFSM e o Centro de Alfabetização Leitura e Escrita (CEALE) da Universidade Federal de Minas Gerais (UFMG) também credenciou a UFSM a integrar a Rede Nacional de Formação Continuada de Professores da Secretaria de Educação Básica do Ministério de Educação, através do Programa Pró-Letramento, no ano de 2008, e posteriormente ao Pacto Nacional pela Alfabetização na Idade Certa, no ano de 2013 (área alfabetização e linguagem) e no ano de 2014 (área matemática), atendendo a formação continuada dos orientadores de estudo dos municípios e dos orientadores de estudo do Estado da metade do Rio Grande do Sul, pois a outra parte está sendo atendida pela Universidade Federal de Pelotas (UFPel).

A visibilidade que este projeto está conquistando deve-se também ao trabalho desenvolvido desde o ano de 2002 e tem sua continuidade devido à percepção que se tem da importância tanto para as acadêmicas e professoras participantes quanto para as crianças que dele se beneficiam em toda a rede de ensino do Estado do Rio Grande do Sul.

Primeiramente, a proposta deste trabalho surgiu do interesse apresentado pelas professoras da área de alfabetização da rede de ensino de Santa Maria e região, que sentiam a necessidade de ampliar suas descobertas e estudos 
nesse campo, para que pudessem desenvolver práticas mais significativas com seus alunos. Partindo dessa iniciativa, a pesquisa foi ampliada para também atender as alunas dos cursos de Pedagogia e Educação Especial da UFSM e oferecer a elas um espaço de aproximação com as escolas e de construção de novas estratégias de alfabetização. Buscou-se, com isso, possibilitar um aprofundamento de seus estudos sobre a compreensão dos modos de organização e das concepções das crianças de anos iniciais do Ensino Fundamental acerca do desenvolvimento da cultura escrita no cotidiano escolar.

Nesse sentido, são propostas estratégias de trabalho que possam propiciar experiências com diversificados materiais e/ou jogos voltados para a alfabetização, letramento e linguagem, envolvendo acadêmicos dos cursos de Pedagogia e Educação Especial da UFSM e professores e alunos dos anos iniciais das escolas participantes do projeto. Espera-se que esse processo se converta em uma experiência significativa, em que a reflexão considere o valor da escrita e da leitura enquanto objetos sociais, permitindo à criança a sua manipulação e apropriação, a fim de que possa transformá-los e recriá-los.

As propostas e estratégias de trabalho são construídas a partir das demandas que surgem das escolas e através de um trabalho coletivo entre professores, alunos e equipe de pesquisadores da UFSM formada por professores do Centro de Educação e também alunos de graduação e pós-graduação.

\section{Reflexões sobre a formação inicial e continuada de professores}

As propostas de formação inicial e continuada de professores, quando desconsideram a memória docente, acabam produzindo ações sem significado para os sujeitos envolvidos nos processos de reflexão sobre seus saberes e fazeres. É preciso, segundo Grillo e Fernandes (2003), que a prática pedagógica não se reduza a questões metodológicas de ensino-aprendizagem, mas que considere a formação como uma prática social, em que o conhecimento seja visto como uma produção histórica e cultural, numa relação dialética entre prática, teoria, sujeitos, saberes, experiências e perspectivas interdisciplinares.

Conforme aponta Antunes (2001), o distanciamento e o desconhecimento sobre as histórias de vida dos professores podem explicar, em certa medida, os motivos que os levam a participarem de cursos e seminários sem conseguirem, na maioria das vezes, articular esses conhecimentos na sua sala de aula. Os conhecimentos transmitidos carecem de sentido e de intensidade para provocar questionamentos e reflexões sobre a prática docente.

No decorrer da história da educação brasileira, o professor sempre foi considerado aquele que só recebia informações e as transmitia para seus alunos. Isso fez com que os saberes oriundos da experiência fossem continuamente ignorados pelo poder instituído. Assim, é muito comum encontrar professores que acabam esperando dos outros as respostas que de certa forma conhecem, mas em 
cujo valor não acreditam. Para Nóvoa (1992), “os professores não produzem os conhecimentos que são chamados a reproduzir, nem determinam as estratégias práticas de ação" (p. 11). Necessitam, segundo Antunes (2001), do crivo e da valorização do outro.

O processo de desvalorização profissional, o desconhecimento da memória docente e o descrédito em relação à produção de saberes docentes acabam contribuindo para o enfraquecimento da autoestima do professor e, consequentemente, da qualidade do ensino na sala de aula. Considerar os professores também como produtores de saberes é um meio de alterar a percepção acerca do que significa o conhecimento e dos processos de formação.

Além disso, a possibilidade de narrar suas histórias de vida como alunos, de refletir, através de processos de formação continuada, sobre os professores que deixaram boas ou más lembranças, suscita recordações que, trazidas ao contexto atual, constituem elementos essenciais na formação e autoformação dos professores. As lembranças escolares e os saberes necessitam ser conhecidos e aproximados dos processos de formação do professor. Esses elementos traduzem experiências que refletem ações, posturas, crenças, práticas e valores que são, segundo Leão (2004), os nossos primeiros saberes sobre a docência. Conforme Tardif (1999, p. 22), "devemos examinar seriamente a natureza desses fundamentos e extrair daí elementos que nos permitam entrar num processo reflexivo e crítico sobre nossas próprias práticas como formadores e como pesquisadores".

Essa percepção é corroborada pela pesquisa desenvolvida por Antunes (2001) com alunas do Curso de Pedagogia e com professores da rede municipal de ensino, utilizando uma metodologia qualitativa que possibilitou a reflexão sobre a memória docente dos sujeitos investigados. Os resultados alcançados apontaram que, ao refletirem sobre suas histórias de vida, incluindo lembranças da escola, escolha profissional, processos de formação e prática pedagógica, os sujeitos instauram novas significações sobre o ser professor nos diferentes ciclos da trajetória profissional. Em contrapartida, ainda segundo Antunes (2001), notou-se, em um número significativo de formandas e em algumas professoras, a presença da "autonomia", compreendida como a capacidade de refletir, criar e construir uma trajetória docente embasada na reflexão e na criatividade.

O relato das histórias de vida dos professores torna-se, assim, um elemento fundamental para acionar o processo de reflexão, inclusive sobre os motivos que levam homens e mulheres a tornarem-se professores. Permite também uma aproximação e compreensão dos fatores que contribuem para o desânimo, a intolerância, o egoísmo, a agressividade e o próprio descrédito em relação à ação docente. Nesse sentido, Nóvoa (1992, p. 23) afirma que "ouvir a voz do professor devia ensinar-nos que o autobiográfico, a vida, é de grande interesse quando os professores falam do seu trabalho". 


\title{
Prática docente e políticas públicas
}

A par das questões que envolvem a prática docente, deparamo-nos ainda com a constante produção teórica no campo da educação, que não raro implica a implantação de políticas públicas de forma indiscriminada em nosso país, frequentemente desconhecendo as diferenças regionais e culturais que caracterizam nosso imenso território. Além disso, chama a atenção a velocidade com que essas políticas sucedem umas às outras: muitas vezes, o professor mal teve o entendimento de uma política pública que está sendo implantada e esta já passa a ser substituída por outra.

Magnani (2000) questiona a aplicação de "novas e revolucionárias teorias" que constantemente os professores são solicitados a adotar em suas salas de aula.

\begin{abstract}
Mudar em relação a quê? O que é esse ensino tradicional? Quando e por que se engendra um tipo de ensino inicial de leitura e escrita que hoje é acusado de antigo e tradicional? O que representa para o momento em que ocorre seu engendramento? Qual a relação com a tradição que lhe é anterior? Como e por que ocorre sua disseminação no tempo? Como se pode explicar sua persistente permanência? Quais os sujeitos que se empenha(aram) na produção do novo e revolucionário? Por que razão e de que maneiras? Qual a relação entre tematizações e concretizações produzidas ao longo da história desse ensino? (MORTATTTI, 2000, p. 20)
\end{abstract}

Questionar o que significa uma prática docente tradicional parece oportuno no momento atual, principalmente quando nos deparamos com tamanho desejo de mudanças na área da educação. Desejamos práticas educacionais inovadoras, críticas, reflexivas e em conformidade com as demandas da realidade na qual estamos imersos. Mas, o que são mudanças na educação? O que significa uma prática docente criativa na sala de aula dentro de uma comunidade? Qual o desejo das crianças e dos jovens que estudam nessas escolas em relação às práticas de leitura e escrita? Pensar sobre ler e escrever faz sentido para as crianças e jovens brasileiros de hoje?

Os desafios são significativos tanto para os pais dessas crianças e jovens quanto para os educadores que permanecem em torno de vinte horas semanais ou mais com eles. Não é uma tarefa fácil, considerando as diferentes culturas, gerações, desejos e significados que estão envolvidas na formação desses professores e alunos.

Nivelar as culturas por uma predominante, a do poder instituído, é uma violência simbólica que por anos a escola vem produzindo através do silenciamento de todos aqueles que pensam e agem de forma diferente do que é permitido e considerado legítimo. Corpos sendo disciplinados pela cópia repetida de palavras sem sentido, desenhos pintados conforme as cores ensinadas, palavras escritas 
conforme o desejo do outro. Mas, onde fica a autonomia? Não se pode ensinar extinguindo a chama criadora de quem ensina e de quem aprende, pois alunos e professores são sujeitos históricos. Em face disso, a progressão por série/ano de estudo, que nem sempre respeita o ritmo de aprendizagem de cada aluno em muitos casos se torna um problema a mais a ser equacionado em sala de aula.

A Resolução CNE/CEB n. 07 de 14/12/2010, no seu artigo 30, inciso III, assegura "a continuidade da aprendizagem, tendo em conta a complexidade do processo de alfabetização e os prejuízos que a repetência pode causar no Ensino Fundamental como um todo e, particularmente, na passagem do primeiro para o segundo ano de escolaridade e deste para o terceiro" e, no parágrafo primeiro do referido artigo, afirma ainda que:

\begin{abstract}
Mesmo quando o sistema de ensino ou a escola, no uso de sua autonomia, fizerem opção pelo regime seriado, será necessário considerar os três anos iniciais do Ensino Fundamental como um bloco pedagógico ou um ciclo sequencial não passível de interrupção, voltado para ampliar a todos os alunos as oportunidades de sistematização e aprofundamento das aprendizagens básicas, imprescindíveis para o prosseguimento dos estudos.
\end{abstract}

Essas determinações nos levam a refletir sobre a necessidade de um trabalho de continuidade que aconteça do $1^{\circ}$ ao $3^{\circ}$ ano do Ensino Fundamental, pois não é admissível que em nosso país milhares de crianças e jovens deixem de concluir o Ensino Fundamental por falta de um trabalho articulado entre os primeiros anos de estudo. Contudo, a referida Resolução, em especial, o artigo 30, não pode ser vista como um incentivo à promoção automática. Muito pelo contrário, é necessário o comprometimento por parte do professor, que deverá realizar um trabalho sério, reflexivo, amoroso e dialógico com as crianças, que nesta faixa etária possuem um enorme desejo de conhecer o ambiente letrado ao seu redor. A Resolução vem assim fortalecer o trabalho articulado e interdisciplinar entre os professores, partindo do entendimento de que a etapa inicial do processo de leitura e escrita não se encerra no primeiro ano de estudo, mas estende-se ao longo do $2^{\circ}$ e do $3^{\circ}$ ano do Ensino Fundamental.

\title{
A metodologia do trabalho desenvolvido
}

A execução do projeto "Laboratório de Alfabetização: repensando a formação de professores" está embasada na metodologia qualitativa, pautada nas reflexões propostas na produção teórica de Bogdan e Biklen (1994), escolhida principalmente por suas características no que concerne aos instrumentos de coleta de informações utilizados ao longo da investigação. Parte-se do entendimento de que a metodologia consiste num processo de reflexão sobre os elementos necessários para auxiliar o pesquisador na compreensão da realidade a ser investigada. Nesse sentido, este é um estudo que busca conhecer o significado de uma metodologia lúdica na construção da cultura escrita pelas crianças que frequentam a primeira série do Ensino Fundamental. 
Conforme estudos desenvolvidos por Bogdan e Biklen (1994), Antunes (2000, 2001) e Deslandes (1994), a interação do pesquisador com os sujeitos constitui-se como um fator significativo nas pesquisas qualitativas, pois permite uma aproximação entre os envolvidos, possibilitando um conhecimento mais profundo do seu contexto sociocultural. Nessa interação, os instrumentos de coleta de informações podem variar de acordo com a natureza da informação a ser coletada.

Na pesquisa em questão, no que concerne ao trabalho com as professoras da escola e com as acadêmicas da UFSM, a coleta acontece através dos relatos autobiográficos, registros em diários e entrevistas semiestruturadas. No caso do trabalho desenvolvido com os alunos das séries iniciais, busca-se perceber, através de observações, o desempenho das crianças e suas necessidades em sala de aula, para então escolher atividades relevantes para serem desenvolvidas. O trabalho com as crianças, com as professoras da escola, bem como com as acadêmicas do Curso de Pedagogia e Educação Especial, é realizado alternadamente, buscando-se sempre a compreensão dos processos investigativos e das significações construídas pelos colaboradores da pesquisa sobre o trabalho e as práticas pedagógicas dele decorrentes. Conforme pode ser lido nos relatos autobiográficos escritos, elaborados pelas alunas participantes desta investigação:

As oficinas que desenvolvemos com as crianças através de jogos que auxiliam sanar as dificuldades que as crianças possuem sobre o processo de construção da leitura e da escrita são ótimas, é um processo criativo pensar em cada uma e como elas nos ajudam a nos colocar no lugar de quem aprende. Aprendemos a trabalhar e planejar coletivamente, a pensar em jogos perante as dificuldades das crianças e buscar respostas e novas perguntas para decifrar os desafios de uma comunidade inserida em uma realidade de vulnerabilidade social. ( $T$, acadêmica do Curso de Licenciatura em Pedagogia da UFSM, $7^{\circ}$ semestre, relato autobiográfico)

Trabalhar no projeto Laboratório de Alfabetização é uma alegria, pois a gente sente a vida da escola entrelaçando na vida da gente. As crianças trazem muitas alegrias e surpresas que só vivencio neste projeto, há quatro anos que me envolvo e me encanto (L, acadêmica do Curso de Licenciatura em Pedagogia da UFSM, $8^{\circ}$ semestre, relato autobiográfico)

Não consigo perceber mais meu envolvimento somente em sala de aula, a participação no projeto em questão tem demonstrado o quanto estou aprendendo sobre o processo de construção da leitura e da escrita. São espaços de reflexão que nos tornam mais capazes de enfrentar os desafios futuros em sala de aula. (D, acadêmica do Curso de Licenciatura em Educação Especial da UFSM, $3^{\circ}$ semestre, relato autobiográfico)

Dando continuidade ao relato das atividades do projeto, no ano de 2007, este foi desenvolvido na Escola Estadual Professora Celina de Morais e na Escola Municipal Luizinho de Grandi. Dele participaram as acadêmicas dos cursos de Pedagogia e Educação Especial da UFSM, professores da rede municipal de ensino 
de Santa Maria, bem como um grupo de crianças que apresentava dificuldades quanto à lecto-escrita. Na Escola Municipal Luizinho de Grandi, trabalhou-se também com a alfabetização de jovens e adultos.

A partir de uma testagem para verificar o nível de lecto-escrita, realizada com o grupo de alunos das séries iniciais do Ensino Fundamental, desenvolveu-se o trabalho voltado para a dificuldade de cada criança, sempre numa perspectiva lúdica. Durante esse período também se desenvolveram pesquisas e discussões na área de alfabetização, a fim de fundamentar práticas pedagógicas para atender aos objetivos do trabalho e dos professores regentes das turmas. Nesse sentido, o planejamento encaminhou-se para suprir as dificuldades relacionadas à leitura, à escrita, à interpretação e ao raciocínio lógico.

Foram utilizados, nos encontros com os alunos, os jogos lúdicopedagógicos oferecidos pelo Gepfica, com financiamento do FNDE/MEC, e atividades lúdicas elaboradas pelas bolsistas do projeto. Os planos de aula, produzidos sob a revisão da professora orientadora, eram baseados em atividades planejadas de acordo com a realidade sociocultural das crianças e sempre considerando as dificuldades de aprendizagem apresentadas.

Planejar sempre foi algo que me deixava muito insegura e apavorada, mas com a participação no projeto o medo foi desaparecendo e a segurança foi sendo conquistada. É um trabalho diário que está me dando segurança e vontade em continuar sendo professora. ( $R$, acadêmica do Curso de Licenciatura em Educação Especial, $3^{\circ}$ semestre UFSM, relato autobiográfico)

Não planejo sozinha, trabalho sempre com minhas colegas e parceiras da equipe do projeto. Considero uma ótima oportunidade, pois já vou aprendendo a trabalhar em grupo, depois quando for professora de fato já terei mais facilidade para interagir com o grupo de colegas. ( $\mathrm{T}$, acadêmica do Curso de Licenciatura em Educação Especial, $3^{\circ}$ semestre UFSM, relato autobiográfico)

O desafio em planejar para estas crianças está em descobrir o que de fato irá auxiliar para que eles aprendam a ler e a escrever. São crianças com 9 anos de idade que ainda não sabem ler e escrever. Não posso cruzar os braços e não fazer nada. Preciso ler e estudar para ajudar estas crianças. ( $\mathrm{C}$, acadêmica do Curso de Licenciatura em Educação Especial, $3^{\circ}$ semestre UFSM, relato autobiográfico)

O planejamento das atividades do projeto é feito em grupo a partir do diagnóstico da realidade na qual as alunas irão atuar. Dessa forma, o planejamento não é feito de forma aleatória, sem o conhecimento da realidade. Conforme as alunas vão ficando mais seguras, elas conseguem sentirem-se ainda mais desafiadas para dar prosseguimento ao projeto. 
É com esta concepção de planejamento, a partir das demandas da realidade, que na Escola Estadual Celina de Moraes desenvolveu-se o trabalho envolvendo 24 participantes, atendendo mais de 40 crianças que apresentavam dificuldades de aprendizagem da $1^{\text {a }}$ à $3^{\text {a }}$ série do Ensino Fundamental. $\mathrm{O}$ apoio institucional por parte da equipe escolar foi imenso desde o primeiro dia, quando os integrantes do grupo de pesquisa estavam apenas de visita à escola, tendo sido preparado, inclusive, um vídeo de boas vindas, no qual se apresentava a realidade dos alunos e da escola.

Ficou combinado com a Direção que um grupo atenderia as turmas de $1^{\mathrm{a}}$ e $2^{\mathrm{a}}$ série e um segundo grupo, os alunos da $3^{\mathrm{a}}$. As crianças eram encaminhadas para o atendimento mediante sugestão da professora regente juntamente com a coordenação, e os encontros aconteciam uma vez por semana, com duração de uma hora, nos turnos manhã e tarde.

As atividades iniciaram-se com um número menor de participantes, mas esse número aumentou logo nas primeiras duas semanas. Isso indica a confiança que a comunidade escolar depositou no projeto e a compreensão dos envolvidos de que cada um precisa fazer a sua parte em relação ao processo de construção da leitura e da escrita.

O planejamento, de responsabilidade da bolsista, era enviado por $e$-mail para as acadêmicas dos cursos do Centro de Educação envolvidas no projeto, que, com autonomia, retiravam ou acrescentavam atividades para melhor atender às necessidades dos alunos, sempre com o auxílio dos jogos para tornar o trabalho ainda mais significativo para as crianças.

No ano de 2008, foram realizados estudos teóricos sobre a construção da lecto-escrita, buscando orientar as acadêmicas e professoras participantes para a etapa seguinte, que foram os encontros com as crianças dos anos iniciais para o posterior desenvolvimento de atividades lúdicas e jogos para a alfabetização. É relevante destacar que foram contempladas mais escolas durante esse ano, o que reforça a importância da continuidade do trabalho.

Também, a partir de 2008, iniciou-se a participação na Rede Nacional de Formação Continuada de Professores, da Secretaria de Educação Continuada e Alfabetização do Ministério da Educação, através do Programa Pró-Letramento e Pacto Nacional para a Alfabetização na Idade Certa - PNAIC. Este programa federal estendeu o desafio da formação continuada de professores à metade do Rio Grande do Sul para a Universidade Federal de Santa Maria (UFSM) e a outra metade à Universidade Federal de Pelotas (UFPel), na área de Alfabetização e Linguagem.

\section{Os resultados da pesquisa}

O trabalho, no ano de 2007, atingiu resultados significativos para todos os participantes: a melhora no aprendizado das crianças e dos adultos envolvidos no projeto, através das aulas ministradas com o auxílio dos jogos 
pedagógicos; a qualificação dos processos formativos dos acadêmicos dos cursos de Educação Especial e Pedagogia da UFSM; o aumento da confiança das comunidades escolares envolvidas em relação ao trabalho desenvolvido pela universidade, especificamente no que tange à atuação do Gepfica.

O envolvimento no projeto "Laboratório de Alfabetização: repensando a formação de professores" é algo que irá permanecer na minha história de vida. Não consigo pensar a minha vida como acadêmica longe deste Projeto. É algo que contagia e nos instiga a continuar na educação. (A, acadêmica do Curso de Licenciatura em Educação Especial, $3^{\circ}$ semestre UFSM, relato autobiográfico)

Entrar numa escola de periferia e saber que muitas crianças que estão matriculadas dependem muito do que aprendem neste espaço educativo. Não consigo imaginar a minha formação desvinculada desta realidade. A teoria que aprendo, o grupo de pesquisa me instiga a criar estratégias para melhorar o cotidiano educativo das crianças. São desafios constantes que me equilibram e me desequilibram: isto é ser um aprendiz de professor. ( $\mathrm{C}$, acadêmica do Curso de Licenciatura em Educação Especial, $3^{\circ}$ semestre UFSM, entrevista semiestruturada)

Acreditamos no trabalho desenvolvido, desenvolvemos este trabalho nas escolas e para as escolas. (V, professora do Curso de Licenciatura em Pedagogia da UFSM, entrevista semiestrurada)

Nos relatos autobiográficos das alunas e da professora envolvidas na pesquisa aparece que a participação no projeto de pesquisa motiva e prepara ainda mais as mesmas para o trabalho articulado entre a universidade e as escolas, oportunizando uma formação interdisciplinar, crítica, reflexiva e principalmente sensível para a transformação da sociedade.

Na Escola Municipal Luizinho de Grandi, os objetivos propostos pelo projeto foram alcançados em sua plenitude, pois foi possível proporcionar aos alunos experiências lúdicas também com a finalidade de melhorar o aprendizado dos adultos, a interação no grupo, a cooperação e a participação nas aulas. As atividades culminaram com uma exposição, no hall da escola, de todos os trabalhos construídos pelos participantes do projeto.

Outro resultado positivo atingido pelo projeto diz respeito aos benefícios para a formação de professores nos cursos do Centro de Educação, já que projeto oportuniza a articulação da graduação não só com a escola, mas também com a pós-graduação, através da interação entre os participantes do projeto, oriundos da graduação e da pós-graduação, o que levou à melhoria na qualificação da produção científica do referido grupo de pesquisa, conforme pode ser lido a seguir:

É muito bom podermos trabalhar a graduação e pós-graduação juntas: pois o que aprendemos na pós-graduação, podemos trocar com as alunas da graduação e vice-versa. Temos a certeza de que a participação de todo este conjunto no grupo nos qualifica 
muito. (J, acadêmica do Curso de Mestrado em Educação da UFSM, relato autobiográfico)

Aprendemos com a nossa orientadora, as mestrandas e doutorandas a possibilidades de aprender a escrever e produzir textos. Isto não é fácil, é um aprendizado que acontece ao longo de uma trajetória, aprendemos cedo pois desde que soube do Gepfica comecei a me envolver e já estou há muito tempo aqui. Às vezes somos as últimas a sair do campus, a exigência é muito grande, mas vale a pena se pensar que com o que estamos aprendendo podemos transformar a educação e a sociedade, se não conseguirmos tudo isto, pelo menos conseguimos nos transformar. (M, acadêmica do Curso de Licenciatura em Pedagogia da UFSM, relato autobiográfico)

Nas escolas onde se desenvolveu a pesquisa, percebeu-se que os professores municipais e estaduais começaram a acreditar com maior convicção de que o processo de leitura e escrita é uma construção de hipóteses que inicia com a escrita pré-silábica e é construída até a hipótese alfabética. Conforme trecho de uma entrevista semiestruturada com uma professora alfabetizadora:

Comecei a perceber que a criança que só copia no seu caderno o que passo na sala de aula ficará anos copiando livros e exercícios sem entender o que ela está fazendo. Não é possível conceber que aprender a ler e a escrever se resume a copiar. Nós professores precisamos fazer mais por estas crianças. Acreditar na psicogênese da leitura e escrita é uma possibilidade. Desafiar com jogos a passagem de um nível para outro já é uma solução. O que não podemos admitir é o uso de cartilhas e cópias indiscriminadas nas salas de aula. (D, professora estadual, entrevista semiestruturada, 15 anos de exercício profissional)

Nesse sentido, entende-se que a busca dos caminhos percorridos pela criança para desenvolver os significados e sua consequente representação é um fator preponderante na criação e no desenvolvimento de propostas mais adequadas e coerentes para a alfabetização e a linguagem. Assim sendo, o projeto objetivou desenvolver trabalhos voltados para pesquisas sobre aquisição da lecto-escrita ao longo dos primeiros anos do Ensino Fundamental, buscando compreender as concepções apresentadas pelas crianças, bem como acompanhar seu desempenho ao longo desse processo. Segundo Ferreiro (1985), a maneira como a criança concebe a leitura e a escrita é ponto de partida para que o professor possa propor uma linha de ação que contemple tais concepções.

Nesse sentido, Luria (1999), Teberosky e Ferreiro (1985) e Ferreiro $(1989 ; 1991)$ buscaram, em suas pesquisas, explicitar como a criança constrói a lecto-escrita, isto é, quais as concepções sobre seus usos e funções. Mais recentemente, Ferreiro (2003, 2004) amplia esses estudos, com uma pesquisa longitudinal feita sobre construções posteriores à consolidação da representação do sistema alfabético. 


\section{Considerações finais}

No decorrer desta pesquisa, observou-se a existência de práticas no Ensino Fundamental que ignoram, na maioria das vezes, a capacidade criadora dos alunos no processo de construção da leitura e escrita, centrando-se em um ensino que somente cumpre o papel de vencer programas e conteúdos, sem se preocupar em desenvolver a autonomia, a criticidade e a criatividade dos envolvidos nos processos de ensino-aprendizagem.

São questões perturbadoras como essas que instigam os pesquisadores do projeto a refletir e a elaborar estratégias conjuntas que possam atenuar e progressivamente extinguir ações docentes acríticas, que subestimam a capacidade de reflexão sobre os processos de leitura e escrita. Não se pode assistir passivamente à perpetuação dessas ações docentes sem construir um conjunto de estratégias para reverter situações que comprometem os processos de alfabetização.

O projeto parte do entendimento de que a memória dos professores constitui um elemento a ser considerado, porque se percebe que as ações docentes estão vinculadas às lembranças dos antigos mestres, da prática pedagógica desenvolvida pela primeira professora - lembranças que possuem força e intensidade e que interferem na forma de ser e sentir-se professor.

Ao longo dos anos de implementação do projeto, verificaram-se vários resultados significativos. Pôde-se perceber o envolvimento nas discussões sobre alfabetização e letramento com a efetiva participação das professoras e acadêmicas dos cursos de Pedagogia e Educação Especial. Também foi possível verificar o interesse do grupo de professores em desenvolver práticas educativas de alfabetização e letramento numa perspectiva lúdica e interdisciplinar, possibilitando uma diminuição progressiva dos índices de evasão nas escolas envolvidas na pesquisa.

O desafio de trabalhar com a comunidade e, principalmente, com as crianças, é muito grande, uma vez que se espera dos acadêmicos e dos professores o desenvolvimento de práticas pedagógicas inovadoras e interativas. Infelizmente, a realidade que ainda confrontamos é o descaso com a alfabetização e o letramento. Num estágio que requer total dinamismo e reflexividade, frequentemente o trabalho é desenvolvido por meio de um processo mecânico de cópia em sala de aula. O Laboratório de Alfabetização vem buscando mudar esta realidade, desde 2002, quando foi criado, e já tem proporcionado grandes mudanças no ensinoaprendizagem das séries iniciais em que atua. O objetivo do projeto é continuar promovendo a interação, de forma cada vez mais efetiva, entre professores e alunos da escola pública e acadêmicos dos cursos de Pedagogia e Educação Especial da UFSM, buscando sempre a tão necessária articulação dessa instituição de ensino com a comunidade. 


\section{Referências}

ANTUNES, H. S. Ser aluna, ser professora: uma aproximação das significações sociais instituídas e instituintes construídas ao longo dos ciclos de vida pessoal e profissional. Tese (Doutorado) - Universidade Federal de Rio Grande do Sul. Porto Alegre: UFRGS, 2001.

ANTUNES, H. S. As lembranças escolares de professores alfabetizadores e a relação com os processos formativos. In: BOLZAN, D. P. V. (Org.). Leitura e escrita: ensaio sobre a alfabetização. Santa Maria, Editora UFSM, 2007. p. 159-171.

BOGDAN, R.; BIKLEN, S. K. Investigação qualitativa em educação: uma introdução à teoria e aos métodos. 4. ed. Portugal: Porto, 1994.

DESLANDES, S. F. Pesquisa social: teoria, método e criatividade. Petrópolis: Vozes, 1994.

FERREIRA, N. T. Para uma nova educação: resgate da imagem poética do professor. In: OLIVEIRA, V. F. de. (Org.). Imagens do professor: significações do trabalho docente. Ijuí: UNIJUÍ, 2000.

FERREIRO, E.; TEBEROSKY, A. Alfabetização em processo. São Paulo: Cortez, 1991.

FERreiro, E.; TEBEROSKY, A. Psicogênese da língua escrita. Porto Alegre: Artes Médicas, 1985.

FERREIRO, E.; TEBEROSKY, A. Reflexões sobre a alfabetização. 14. ed. São Paulo: Cortez, 1989.

LEÃO. D. O. de. Memória e saberes de alfabetizadoras: representações sobre a leitura e escrita na história de vida de três professoras. Dissertação (Mestrado) - Universidade Federal de Santa Maria. Santa Maria: UFSM, 2004.

LURIA, A. R. Desenvolvimento cognitivo: seus fundamentos culturais e sociais. Trad. Fernando Limogeli Gurgueira. São Paulo: Ícone, 1990.

MAGNANI, M. do R. M. Os sentidos da alfabetização: a questão dos métodos e a constituição do objeto de estudo. Presidente Prudente: UNESP, 1997.

NÓVOA, A. Formação de professores e profissão docente. In: NÓVOA, A. (Org.). Os professores e a profissão. Lisboa: Dom Quixote, 1992.

TARDIF, M. Os saberes docentes e a formação profissional. Petrópolis: Vozes, 2002.

* Helenise Sangoi Antunes - Professora Doutora da Universidade Federal de Santa Maria, Santa Maria, Rio Grande do Sul, Brasil.

\section{Correspondência}

Helenise Sangoi Antunes - Av. Nossa Senhora das Dores, 740

CEP: 97050-530, Santa Maria, Rio Grande do Sul, Brasil.

E-mail:professora@helenise.com.br

Recebido em 02 de outubro de 2012

Aprovado em 25 de março de 2013 
